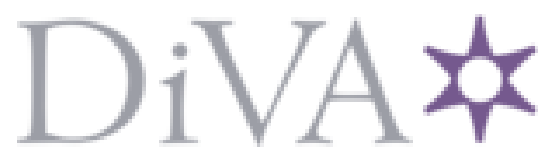

http://www.diva-portal.org

This is the published version of a paper published in Tellus. Series B, Chemical and physical meteorology.

Citation for the original published paper (version of record):

Heintzenberg, J., Leck, C., Birmili, W., Wehner, B., Tjernström, M. et al. (2006)

Aerosol number-size distributions during clear and fog periods in the summer high Arctic: 1991, 1996 and 2001.

Tellus. Series B, Chemical and physical meteorology, 58: 41-50

http://dx.doi.org/DOI: 10.1111/j.1600-0889.2005.00171.x

Access to the published version may require subscription.

N.B. When citing this work, cite the original published paper.

Permanent link to this version:

http://urn.kb.se/resolve?urn=urn:nbn:se:su:diva-109524 


\title{
Aerosol number-size distributions during clear and fog periods in the summer high Arctic: 1991, 1996 and 2001
}

\author{
By JOST HEINTZENBERG ${ }^{1 *}$, CAROLINE LECK ${ }^{2}$, WOLFRAM BIRMILI ${ }^{1}$, \\ BIRGIT WEHNER ${ }^{1}$, MICHAEL TJERNSTRÖM ${ }^{2}$ and ALFRED WIEDENSOHLER ${ }^{1}{ }^{1}$ Leibniz \\ Institute for Tropospheric Research, Permoserstr. 15, 04318 Leipzig, Germany; ${ }^{2}$ Department of Meteorology, \\ Stockholm University, S-10691 Stockholm, Sweden
}

(Manuscript received 2 June 2005; in final form 30 August 2005)

\begin{abstract}
The present study covers submicrometer aerosol size distribution data taken during three Arctic icebreaker expeditions in the summers of 1991, 1996 and 2001. The size distributions of all expeditions were compared in log-normally fitted form to the statistics of the marine number size distribution provided by Heintzenberg et al. (2004) yielding rather similar log-normal parameters of the modes. Statistics of the modal concentrations revealed strong concentration decreases of large accumulation mode particles with increasing length of time spent over the pack ice. The travel-time dependencies of both Aitken and ultrafine modes strongly indicate, as other studies did before, the occurrence of fine-particle sources in the inner Arctic.

With two approaches evidence of fog-related aerosol source processes was sought for in the data sets of 1996 and 2001 because they included fog drop size distributions. With increasing fog intensity modes in interstitial particle number concentrations appeared in particular in the size range around $80 \mathrm{~nm}$ that was nearly mode free in clear air.

A second, dynamic approach revealed that Aitken mode concentrations increased strongly above their respective fog-period medians in both years before maximum drop numbers were reached in both years. We interpret the results of both approaches as strong indications of fog-related aerosol source processes as discussed in Leck and Bigg (1999) that need to be elucidated with further data from dedicated fog experiments in future Arctic expeditions in order to understand the life cycle of the aerosol over the high Arctic pack ice area.
\end{abstract}

\section{Introduction}

Largely disconnected from continental aerosol sources (Heintzenberg and Larssen, 1983) and under the influence of efficient wet scavenging processes of widespread Arctic stratus (Curry, 1986; Intrieri et al., 2002), total aerosol particle numbers down to $1 \mathrm{~cm}^{-3}$ and particulate mass concentrations well below $1 \mu \mathrm{g} \mathrm{m}^{-3}$ have been measured in the marginal ice zone of the summer Arctic (Lannefors et al., 1983; Covert et al., 1996; Leck and Persson, 1996a). Therefore, in summer, the high Arctic traditionally had been seen as being one of the cleanest regions in the global troposphere. However, there are no land stations north of $83^{\circ} \mathrm{N}$ and prior to 1991 no atmospheric shipor ice-based research was conducted north of the marginal ice zone.

Long-term aerosol measurements in the Canadian high Arctic and on Spitsbergen gave the first indications of natural Arc-

\footnotetext{
*Corresponding author.

e-mail: jost@tropos.de

DOI: $10.1111 /$ j.1600-0889.2005.00171.x
}

tic aerosol sources though increased concentrations of particulate methane sulfonate (MSA) in summer (Barrie et al., 1992; Heintzenberg and Leck, 1994).

The International Arctic Ocean Expedition 1991 provided the first detailed aerosol measurements north of $83^{\circ} \mathrm{N}$ (Leck et al., 1996). Both chemical (Leck and Persson, 1996a; Maenhaut et al., 1996) and physical aerosol characteristics (Covert et al., 1996; Wiedensohler et al., 1996) indicated local aerosol sources deep inside the pack ice region. However, the source processes could not be fully illuminated. The follow-up expedition in 1996 extended the aerosol studies in the high summer Arctic (Leck et al., 2001) and generated a new hypothesis concerning natural particle sources (Leck and Bigg, 1999). The third International Arctic Ocean Expedition in summer 2001 (AOE-2001, Leck et al., 2004) repeated many of the previous aerosol measurements while adding a substantial biological component to follow up on the ideas of Leck and Bigg (1999) and Leck et al. (2001) concerning possible aerosol source processes related to biological films on open leads in the pack ice and coupled to fog periods. AOE-2001 also carried a substantially enhanced boundarylayer meteorological component that allowed a more detailed 


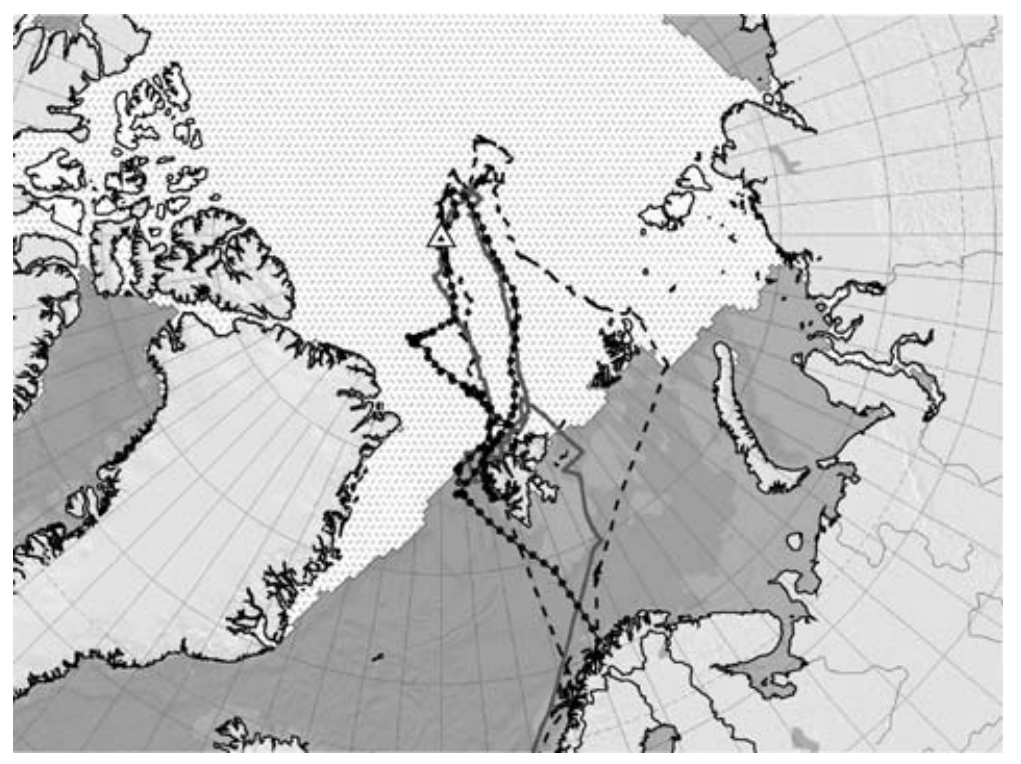

Fig. 1. Routes of the three International Arctic Ocean Expeditions in 1991, 1996 and 2001.

analysis of the meteorological conditions relevant to the aerosol formation.

The new hypotheses on marine aerosol formation were connected to the occurrence of fogs or low clouds. These systems traditionally are mainly seen as particle sinks (e.g. Heintzenberg et al., 1998). A few observations exist that indicate gas-to-particle formation processes in the vicinity of clouds (Radke and Hobbs, 1991; Wiedensohler et al., 1997; Clarke et al., 1998; 1999). However, no mechanisms have been deduced from these studies that could explain the new particle formation in the Aitken diameter range $(25-70 \mathrm{~nm})$ as hypothesized in the summer Arctic (Leck and Bigg, 1999).

With comparable techniques submicrometer particle size distributions have been measured during all three Arctic expeditions. The aerosol results of 1996 and 2001 have not been published yet. Thus, the present three-pronged study was carried out:

1. To synthesize the size distributions of all three expeditions and compare them to the statistics of the marine number size distribution provided by Heintzenberg et al. (2004).

2. To study aerosol characteristics and related processes over the pack ice covered inner Arctic.

3 . To search for evidence of fog-related aerosol source processes hypothesized by Leck and Bigg (1999) in the combined data set.

\section{Experimental}

The analyses presented here rely on measurements carried out from the icebreaker Oden between latitude $74-90^{\circ} \mathrm{N}$ from beginning of July to mid-September. Figure 1 shows the routes of all three expeditions. The southern limits of the ice covered central Arctic Ocean is also shown in terms of average limits of 25\% ice coverage for the August months of 1979-2002. The ship encountered a transition from the 'marginal ice zone' having $20-70 \%$ ice cover and the 'pack ice region' having between 70 and $90 \%$ ice cover. Surface air temperatures were usually in the range $-1.5^{\circ} \mathrm{C}$ to $0^{\circ} \mathrm{C}$. Until mid-September the sun was continuously above the horizon, though commonly obscured by clouds.

An identical PM10-inlet was utilized in all expeditions upstream of all aerosol measurements. The inlet with the impactor was located $27 \mathrm{~m}$ above the sea surface, $3 \mathrm{~m}$ above the roof of the laboratory container. Direct contamination from the ship was excluded by using a pollution controller. Provided that the wind was within $\pm 70^{\circ}$ of the direction of the bow and stronger than $2 \mathrm{~m} \mathrm{~s}^{-1}$, no pollution reached the sample inlets. Differential mobility analysers (DMAs) were deployed in all experiments to measure the number size distributions of dry submicrometer particles. The 1991 set up for aerosol measurements yielded a complete number size distribution from $3 \mathrm{~nm}$ to $500 \mathrm{~nm}$ diameter in 34 intervals of diameter every 10 minutes. More details of the 1991 set up for aerosol measurements are given in Covert et al. (1996). For the 1996 expedition aerosol size distributions were measured in 27 intervals between 5 and $600 \mathrm{~nm}$ diameter. Leck et al. (2001) reported further details.

The counters used in the DMPS were size and concentration calibrated against an electrometer and the TSI 3025 in the standard way (Stolzenburg, 1988). The TSI 3010 measuring total particle concentration was not calibrated for the present study. Instead, factory calibrations were used to interpret the data.

In 2001 the system described in Birmili et al. (1999) was used for the measurement of dry number size distributions of 
submicrometer aerosol particles. It consists of two DMA-based spectrometers with overlapping size ranges working in parallel similar to the 1996 set up. However, a TSI-3025 CPC was used for the particle range between 3 and $20 \mathrm{~nm}$ and a TSI-3020 CPC for the range 10-900 $\mathrm{nm}$. The total diameter range was scanned in 12 minutes in 41 size steps. The transfer functions of both DMA's and the size-dependent counting efficiencies of both CPCs had been calibrated before the experiment.

For fog measurements an aspirated commercial fog drop spectrometer (FSSP 100, PMS Inc., Boulder, CO) was utilized. The FSSP was located on the roof of the laboratory container. In 1996 it was pointing in a fixed position towards the bow of the ship resulting in a dependency of its results on wind direction. This fixed position of the FSSP may have caused losses of larger drops controlling liquid water content (LWC) in some fogs.

Arctic fogs exhibit rather low drop numbers and LWC. Kumai (1973) reported drop concentrations between 0.4 and $24 \mathrm{~cm}^{-3}$ with LWC between 0.006 and $0.15 \mathrm{~g} \mathrm{~m}^{-3}$ and most frequent drop diameters around $10 \mu \mathrm{m}$. Most of the fog data were collected on station, which meant that the ship was oriented so that the wind was within $\pm 70^{\circ}$ of the direction of the bow. In 2001, mounting the instrument on a wind vane alleviated this problem. The FSSP was not calibrated specifically for the present study. Instead, factory calibrations were used to interpret these data. The size range of FSSP covered diameters from $3 \mu \mathrm{m}$ to $47 \mu \mathrm{m}$ with a measurement cycle of 10 minutes. The measured drop number size distributions were also converted to mass size distributions assuming spherical drops with a density of $1 \mathrm{~g} \mathrm{~cm}^{-3}$. The drop size distributions were integrated to derive the total drop number $N_{\mathrm{d}}$ in $\mathrm{cm}^{-3}$ and the LWC in $\mathrm{g} \mathrm{m}^{-3}$.

During all three experiments, continuous meteorological surface observations were made from a ship-based weather station. Radiosonde releases were also performed at 6-h intervals when the ship was stationary, to measure vertical profiles of temperature, relative humidity wind direction and wind speed. These were useful in interpreting changes in the boundary layer stability and mixing that could influence particle concentrations. AOE-2001 also carried a more extensive set of boundary-layer measurements, allowing a more detailed analysis of the relevant meteorological processes (cf. Tjernström et al. (2004a; 2004b) for a detailed discussion). In addition to the ships weather station, a micrometeorological observation site was deployed on the ice for a 3-week ice drift that was part of AOE-2001. This provided more detailed surface observations during this phase of the 2001 experiment. An array of remote-sensing instruments was also part of AOE-2001. Cloud radar and a passive scanning microwave radiometer provided a nearly continuous monitoring of the vertical structure of the clouds and of temperature. A wind profiler likewise provided near-continuous observations of the vertical wind profiles while a sodar system deployed on the ice provided boundary-layer winds during the ice drift.
Table 1. Time periods and number of quality-controlled and log-normally fitted size distributions measured north of $74^{\circ} \mathrm{N}$, and with travel times Mtr $>24 \mathrm{~h}$ from the ice edge inwards during the three International Arctic Ocean Expeditions in 1991, 1996 and 2001.

\begin{tabular}{lcccc}
\hline Year & $\begin{array}{c}\text { Time } \\
\text { period }\end{array}$ & $\begin{array}{c}\text { Records } \\
>74^{\circ} \mathrm{N}\end{array}$ & $\begin{array}{c}\text { Records } \\
\text { Mtr }>24 \mathrm{~h}\end{array}$ & $\begin{array}{c}\text { Records Clear, } \\
\text { Mtr }>24 \mathrm{~h}\end{array}$ \\
\hline 1991 & August 1-October 10 & 1094 & 545 & 271 \\
1996 & July 13-September 23 & 4335 & 2577 & $536^{\mathrm{a}}$ \\
2001 & July 1-August 25 & 4856 & 3737 & $415^{\mathrm{a}}$ \\
\hline
\end{tabular}

a) 1996 and 2001 the 'clear' classification was sharpened by requiring fog drop number concentration NFSSP to be $<0.01 \mathrm{~cm}^{-3}$.

\section{Data set and data processing}

The total set of aerosol size distribution data covers different parts of the three summers of 1991, 1996 and 2001 as detailed in Table 1 . Because of the short and pronounced biologically active summer season (Leck and Persson, 1996b) differences of weeks in the timing of the three expeditions can be expected to result in significant differences in measured aerosol properties. For the clear-air statistics of size distributions all data taken north of $74^{\circ} \mathrm{N}$ were considered. Depending on the year the number of size distributions measured north of this limit ranged between 1000 and 7000. For the process-related studies discussed in Section 4.2 the additional constraint of back trajectory travel times over the pack ice $>24 \mathrm{~h}$ was introduced.

In order to harmonize und interpret the combined data set the following processing was applied:

1. Elimination of contaminated records with $\mathrm{CPC}$ and, in 2001, with additional trace gas information (Armin Wisthaler, private communication)

2. Interpolation of the size distributions on a common grid of 41 sizes from 3.7 to $613 \mathrm{~nm}$ dry diameter

3. Fitting of two to four log-normal functions to the size distributions according to the method described in Heintzenberg et al. (2004). Whereas the input size range to the fitting procedure corresponded to the range given under 2.), the geometric mean diameters of the log-normal fitting functions were allowed to vary between 1 and $1000 \mathrm{~nm}$.

4. Geopositioning of all records with logged ship positions

5. Three-dimensional 5-d backward air trajectories at 6-h intervals arriving at the ship's position at a height within the boundary layer were constructed for all three periods considered. They were calculated with the 1996 version of the (McGrath, 1989) model of the European Center of Medium-range Weather Forecasts (ECMWF) using their analysed wind and pressure fields. Nilsson (1996) found that they will resolve surface and line sources $>5 \mathrm{~d}$ backward and point or small surface sources $2-4 \mathrm{~d}$ over the central Arctic Ocean. The time elapsed since the air was last in contact with the marine source (using current ice maps; 
National Ice Centre, USA and the ARTIST Sea Ice Algorithm from the University of Bremen, Germany with input from daily polar gridded brightness temperature measured by the SSM/I, special Sensor Microwave Imager) were in addition calculated for each trajectory, hereafter referred to as Mtr.

6. Samples taken north of the ice edge in air that subsided from the free troposphere within $45 \mathrm{~h}$ (using weather maps and soundings) before arrival at the measuring site were excluded from the data set to minimize influences of other than boundary layer aerosol sources.

7. Classification according to 'clear' and cloudy or foggy, where clear was made according to the hourly or half-hourly meteorological surface meteorological observations during the expedition in 1991. In 1996 and 2001 the additional criterion of total drop number concentration as measured by the FSSP < $0.01 \mathrm{~cm}^{-3}$ was utilized to define 'clear' periods.

First interpretations of the 1996 data and the results of the fast pulse height analysers connected to UCPCs in 1991 (Covert et al., 1996) and 1996 (not shown here) had indicated frequent occurrences of new particle nucleation. In order not to miss any such events we refrained in the present study from applying the criteria of eliminating all particle data with nominal Poisson counting errors of $100 \%$ and larger.

\section{Results and discussion}

\subsection{Statistics of the clear air size distribution}

Aerosol data from four cruises over North and South Atlantic, Indian Ocean and Pacific taken with very similar aerosol instrumentation as on the Arctic expeditions have been analysed by Heintzenberg et al. (2004) to derive statistical information on the shape of the submicrometer marine aerosol size distribution. The ship-borne data in Heintzenberg et al. (2004) were taken on transits to specific working areas without detailed meteorological records that would allow differentiating foggy from clear periods. However, the respective routes can be expected to be largely free from fog events. In the summer Arctic, on the other hand, low stratus clouds and fogs are very frequent (Huschke, 1969; Curry, 1986; Intrieri et al., 2002). Furthermore, closely related to boundary-layer fog and cloud formation, the occurrence of pack ice strongly controls all processes at the sea surface (Tjernström, 2005). In order to allow a comparison of the Arctic aerosol statistics with the corresponding data from Heintzenberg et al. (2004) only fog and cloud-free Arctic data were considered according to constraint six in Section 3. The extent of the respective sub sets of data is given in Table 1 .

In the marine aerosol data from southern latitudes the frequency of occurrence of geometric mean diameters $f_{\mathrm{n}}\left(d_{\mathrm{g} 0}\right)$ exhibited four maxima, which led to the discussion of the four modes: 'ultrafine' (1-25 nm), 'Aitken' (25-70 nm), 'accumulation' (70-250 nm) and 'large accumulation' (250-1000 nm) in

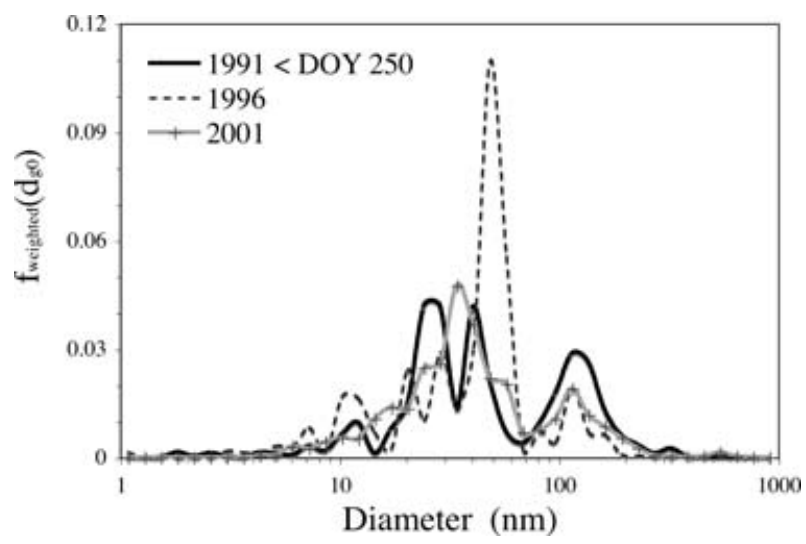

Fig. 2. Frequency of occurrence $f_{\mathrm{n}}\left(d_{\mathrm{g} 0}\right)$ of geometric mean diameters in the submicrometer summer Arctic aerosol in the three Arctic Ocean Expeditions (cf. Table 1 for details on the expeditions). For 1991 only data with Day of the Year (DOY) $<250$ were used (see text for details).

the submicrometer size distribution. An inspection of $f_{\mathrm{n}}\left(d_{\mathrm{g} 0}\right)$ of the three Arctic expeditions in Fig. 2 reveals a somewhat different picture. In the ultrafine size range relative maxima of $f_{\mathrm{n}}\left(d_{\mathrm{g} 0}\right)$ are found at different diameters in different years. In the Aitken range the absolute maxima of $f_{\mathrm{n}}\left(d_{\mathrm{g} 0}\right)$ were found in all years. However, considerable structure appears and year-to-year variability appears in this range as well. The accumulation range exhibits more similar frequencies of occurrences of $d_{\mathrm{g} 0}$ with the maxima being located in a narrow size range. The large accumulation mode is hardly visible in any year, largely because of an upper size limit of $613 \mathrm{~nm}$ in the interpolated data, low winds in the marginal ice zone and the majority of data having been taken within the pack ice. We note that in 1991 data later than Day of the Year (DOY) 250 were excluded from the statistics in Fig. 1 because the biologically active season ended and continentally polluted air masses prevailed later (Leck and Persson, 1996a).

For comparison with the grand average (GA) marine aerosol data we calculated the statistics of the log-normally fitted Arctic size distributions in the four modal ranges mentioned above. This comparison is reported in Table 2. Figure 3 compares the positions of the median values of $d_{\mathrm{g} 0}$ in the different years with the respective GA marine values to emphasize the similarity of the modal positions in both Arctic and the GA marine aerosol.

When comparing Arctic modal number concentrations with GA marine conditions the traditional view of source-free inner Arctic is only confirmed in modes three and four. Median concentrations in the Aitken mode are about two-thirds of the respective GA marine value. The even larger difference in nucleation mode medians may be in part due to the different statistical cleaning process applied to the GA marine data set (Heintzenberg et al., 2004) as compared to the Arctic data to which this process was not applied. 
Table 2. Median log-normal fit parameters of the marine submicrometer number size distribution of aerosol particles (cf. Table 1 for details of the experiments). The Arctic data hold for Latitudes $>74^{\circ} \mathrm{N}$, travel time Mtr from the ice edge $>24 \mathrm{~h}$ and clear sky conditions. GA $=$ grand average Arctic (1991-2001). GA = grand average Marine (1995-2001) (Heintzenberg et al., 2004). $d_{\mathrm{g} i}=$ geometric mean diameters (nm). $N_{i}=$ total number $\left(\mathrm{cm}^{-3}\right), \sigma_{\mathrm{g} i}=$ geometric standard deviations. $i=1$ : ultrafine mode; $i=2$ : Aitken mode; $i=3$ : accumulation mode; $i=4$ : large accumulation mode

\begin{tabular}{|c|c|c|c|c|c|c|c|c|c|c|c|c|}
\hline Experiment & $d_{\mathrm{g} 1}$ & $d_{\mathrm{g} 2}$ & $d_{\mathrm{g} 3}$ & $d_{\mathrm{g} 4}$ & $N_{1}$ & $\mathrm{~N}_{2}$ & $N_{3}$ & $N_{4}$ & $\sigma_{\mathrm{g} 1}$ & $\sigma_{\mathrm{g} 2}$ & $\sigma_{\mathrm{g} 3}$ & $\sigma_{\mathrm{g} 4}$ \\
\hline 1991 & 11 & 35 & 135 & 328 & 22 & 31 & 20 & 1.4 & 1.3 & 1.4 & 1.4 & 1.3 \\
\hline 1996 & 11 & 46 & 143 & 528 & 92 & 375 & 19 & 0.72 & 1.3 & 1.4 & 1.4 & 1.3 \\
\hline 2001 & 17 & 36 & 133 & 470 & 54 & 60 & 19 & 0.95 & 1.3 & 1.4 & 1.4 & 1.2 \\
\hline GA Arctic & 12 & 41 & 130 & 427 & 52 & 91 & 20 & 1.1 & 1.3 & 1.4 & 1.4 & 1.2 \\
\hline GA Marine & 18 & 43 & 149 & 487 & 0 & 146 & 98 & 4 & 1.3 & 1.4 & 1.4 & 1.4 \\
\hline
\end{tabular}

\subsection{Dependence of modal concentrations on travel time from ice edge}

As we are interested in the aerosol characteristics and related processes of the pack ice covered inner Arctic, we would like to eliminate the influence of open southern waters and of the marginal ice zone. The former influence was minimized by excluding all data south of $74^{\circ} \mathrm{N}$. As a means to investigate the latter we classified clear-air modal concentrations as a function of travel time from the ice edge in $24 \mathrm{~h}$ bins up to the maximum length of $120 \mathrm{~h}$ of the back trajectories. All travel times (Mtr) estimated to be larger than $120 \mathrm{~h}$ were collected in bin 120$144 \mathrm{~h}$.

The travel-time dependencies of the concentrations in the four modes are collected in Fig. 4. As indication of the variability of the data 25th and 75th percentiles are shown as 'error bars' in the graphs. Travel-time statistics are presented only for at least five cases per time bin and mode.

Losses of particles to the surface will be highest on the first or second day when drizzle and sedimentation of fog drops cause

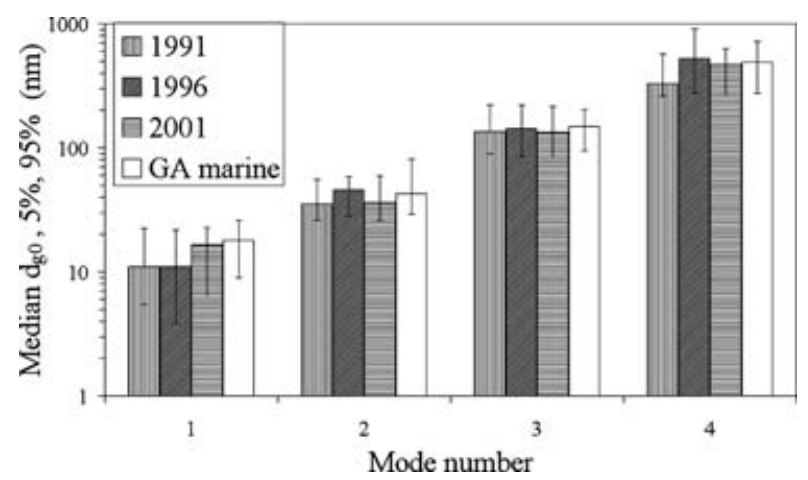

Fig. 3. Median positions of the geometric mean diameters $d_{\mathrm{g} 0}$ in the four modes (1) 'ultrafine', (2) 'Aitken', (3) accumulation' and (4) 'large accumulation' of the three Arctic Ocean Expeditions in Table 1 compared to the grand average (GA) marine results of Heintzenberg et al. (2004). The results hold for clear conditions and travel times Mtr from the ice edge with Mtr $>24 \mathrm{~h}$. The 5th and 95th percentiles are given as error bars about the median results. effective wet scavenging as warm moist air is advected in over the pack ice. In accordance with the conventional understanding of a source-less high summer Arctic large accumulation mode concentrations would be expected to decline rapidly within $24 \mathrm{~h}$ travel time from the ice edge and remain low over the pack ice (cf. Fig. 4d). This trend is less clearly seen in the accumulation mode, most clearly in 1996 (cf. Fig. 4c). In the Aitken mode, no consistent concentration decrease with increasing travel time from the ice edge is apparent. In contrast, depending on the year, and thus position in the strong seasonal biological cycle, substantial concentration increases were observed in the inner Arctic. In 1991 even the highest Aitken concentrations were measured with maximum travel times. Even higher variability with travel time is seen in the ultrafine mode with strong concentration increases at long travel times from the ice edge. The travel-time dependencies of both Aitken and ultrafine modes strongly indicate the occurrence of fine particle sources over the inner Arctic in accord with the interpretations of (Leck and Bigg, 2005).

In Leck and Bigg (2005) transmission electron microscopy (TEM) photographs of airborne particles were compared with those of particles found in the surface microlayer of the open water between ice floes (Bigg et al., 2004). The similarity in morphology (closely resembling microcolloidal aggregates or 'virus-like particles'), physical properties, X-ray spectra and a chemical reaction of the numerous aggregates and their building blocks and of bacteria and other micro-organisms found in both, strongly suggests that the airborne particles were ejected from the water by bursting bubbles. Individual components of the aggregates were too small to be captured efficiently with the TEM collectors used, but the fact that they were the only particle types observed that were smaller than $70 \mathrm{~nm}$ diameter suggests that they formed the bulk of such size of particles seen by the DMPS. The close agreement between the size distributions obtained from TEM photographs of the aggregates and their individual components and that of the DMPS between 15 and $70 \mathrm{~nm}$ (Aitken mode) thus strongly indicate the occurrence of fine particle sources over the inner Arctic. 

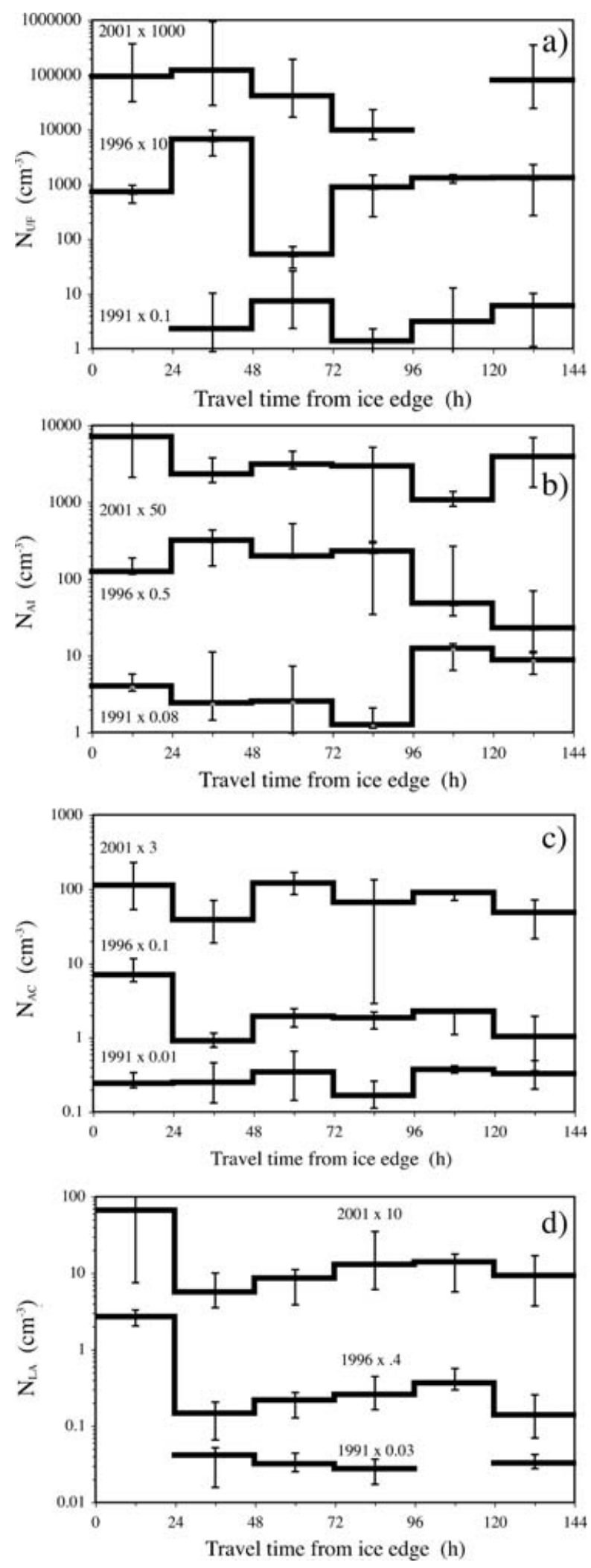

Fig. 4. (a) Ultrafine median modal concentrations of the three Arctic Ocean Expeditions in Table 1 as a function of travel time from the ice edge; (b) same but for Aitken modal concentrations; (c) same but for

\subsection{Influence of fog periods}

In 1996 and 2001 drop spectrometers (FSSP) were available to delineate and quantify fog passages and their potential effects on the submicrometer aerosol. With the help of the FSSP data two investigations were conducted. First, the frequency of occurrence of modal diameters $d_{\mathrm{g} 0}$ was calculated as a function of total drop number concentration $N_{\mathrm{FSSP}}\left(\mathrm{cm}^{-3}\right)$. For that purpose three subpopulations of interstitial particle size distributions were formed: (a) $N_{\mathrm{FSSP}}>0.1 \mathrm{~cm}^{-3}$, (b) $N_{\mathrm{FSSP}}>1 \mathrm{~cm}^{-3}$ and (c) $N_{\text {FSSP }}>10 \mathrm{~cm}^{-3}$. The frequencies of occurrence were weighted with the respective modal concentrations. In order to emphasize the changes in particle size distributions with non-fog conditions, the weighted frequencies were normalized by the respective values in clear air $\left(N_{\mathrm{FSSP}}<0.01 \mathrm{~cm}^{-3}\right)$. The results of this analysis are collected in Figs. 5a and 5 b.

In both 1996 and 2001 systematic changes of the interstitial aerosol occurred with increasing number of fog drops. In clear air geometric mean diameters were most frequent in the range $30-60 \mathrm{~nm}$ and a consistent minimum in occurrences was found between 70 and $90 \mathrm{~nm}$ (cf. Fig. 2). In fogs, and increasingly so with increasing drop number, the situation reversed. Much less frequently occurring modes were found in the clear-air Aitken range (30-60 nm) while a strong increase of occurrences fell right into the minimum between Aitken and accumulation range. Relative to clear-air conditions further strong increases of mode occurrences were found in both years above $100 \mathrm{~nm}$ diameters.

These findings are incompatible with conventional understanding of aerosol scavenging processes in fogs or clouds, from which one would have expected increasing scavenging of accumulation mode and ultrafine particles with increasing strength of fogs. In particular, the most frequent appearance of particle modes right in the clear-air gap between Aitken and accumulation mode we interpret as strong indication of particle source processes in the fogs of the inner summer Arctic.

In a second, dynamic approach, fog periods were defined with a FORTRAN-programmed algorithm searching through the FSSP time series according to the following criteria:

1. A fog period starts when the total drop number $N_{\mathrm{d}}$ reaches above a threshold called ANT.

2. The LWC exceeds a threshold called AMT for at least $N 1$ records (with $10 \mathrm{~min}$ per record) during the fog period.

accumulation modal concentrations and (d) same but for large accumulation modal concentrations. The modal concentrations are collected in $24 \mathrm{~h}$ bins. Concentration values for the different years are shifted by the factors given after the year in order to avoid overlapping curves. Only time bins with at least five cases are shown. The 25th and 75 th percentiles are given as error bars. 

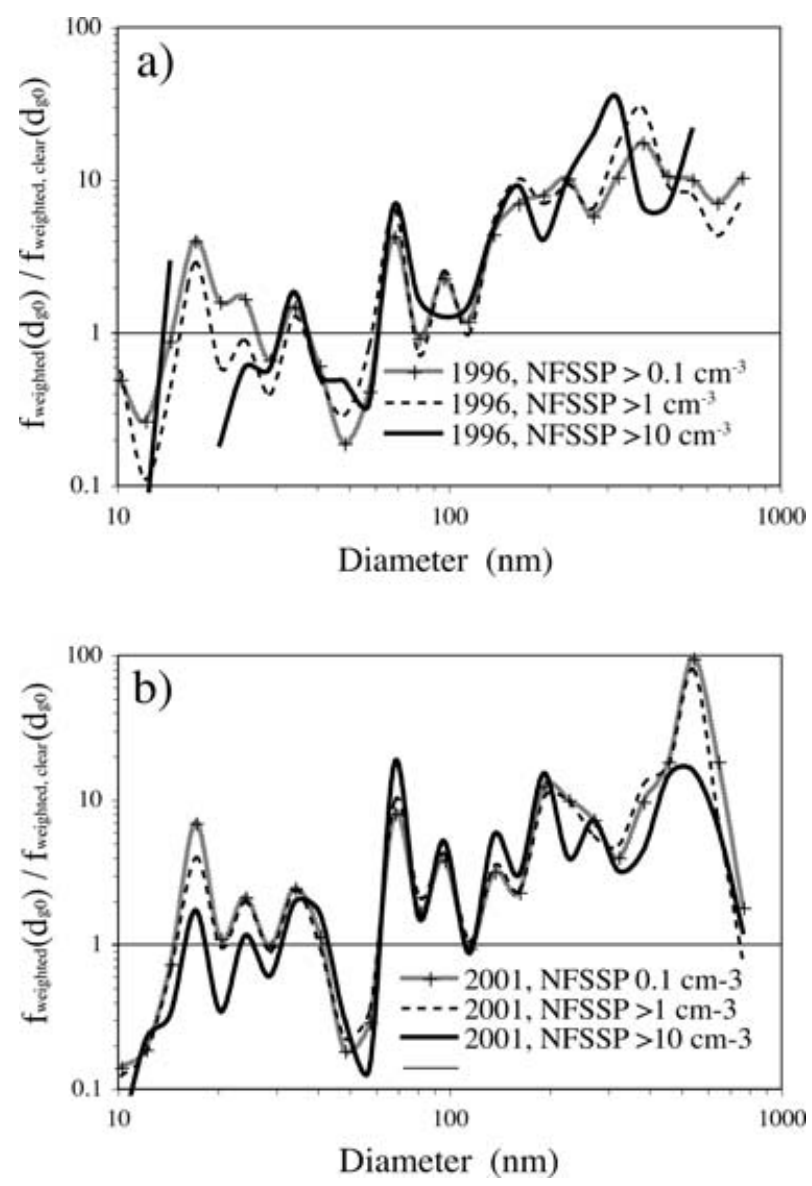

Fig. 5. (a) Normalized frequencies of occurrence of geometric mean diameters $f_{\text {weighted }}\left(d_{\mathrm{g} 0}\right) / f_{\text {weighted,clear }}\left(d_{\mathrm{g} 0}\right)$ in 1996 for three groups of total number concentration $N_{\mathrm{FSSP}}$ in $\mathrm{cm}^{-3}$ of fog drops and (b) same but for the year 2001. The frequencies of occurrence were weighted with the respective modal concentrations. Travel times Mtr from the ice edge were greater than $24 \mathrm{~h}$.

3. During the fog period $N_{\mathrm{d}}$ may fall below ANT for no more than $N 2$ records.

4. The fog period ends at a return of $N_{\mathrm{d}}$ below ANT.

5. The fog period then has a total length of at least $N 3$ records.

6. $N_{\mathrm{d}}$ then stays below ANT for at least $N 4$ records.

The N4 records after the end of a fog period were added because observations during the expeditions hinted at particle production during post-fog periods. For a synopsis of the aerosol evolution over fog periods of different lengths we normalized the time axis of each fog period by the total length of the respective fog period (including the post-fog period). Thus, the subsequent results are presented as a function of the fraction of the fog events (covering the scale 0-1). Size-dependent particle concentrations during the analysed fog periods varied over a wide range. To facilitate comparisons we normalized the modal concentrations
$N_{\text {Mod }}$ of each fog period by the median modal concentrations $N_{\text {Mod,median }}$ taken over the respective period.

With the 2001 times series of FSSP and aerosol data the six fog-defining parameters introduced above were varied manually until maximum increases in $N_{\text {Mod }}$ were reached and, at the same time, a minimum of at least 10 fog periods were retained for a statistics of the aerosol evolution during the respective periods. Moreover, the more extensive meteorological observations available during 2001 were used to investigate the resulting fog periods. Thus, all resulting fogs periods from the 2001 expedition were studied in some detail and the criteria were altered to exclude questionable cases, for example, fogs occurring during a frontal passage (change of air mass), until a consistent set of fog periods remained. It is important to realize that this procedure was not used to subjectively remove any of the cases from the study, but only to aid in the selection of the fog-defining criteria. The remaining fog periods after this procedure roughly fall into three categories: 'Air mass fogs' (30\%), 'dynamic fogs' (42\%) and 'frontal fogs' (28\%). So-called 'air mass fogs' occur without any changes in the dynamic parameters and include, for example, pure radiation fogs that appear when the overlying clouds thin or evaporate and the near-surface air cools due to radiative processes. The so-called 'dynamic fogs' are perhaps the most interesting category. In these cases there was a systematic change in dynamic parameters and the vertical structure of the lower troposphere. Often the initiation of such a fog coincided with a front-like feature, with a rapid change in temperature, boundarylayer depth and sometimes with a burst of drizzle. However, no air mass change could be detected and all changes were confined to the fog layer - the boundary layer. For lack of a better name we can call these events 'mesofronts' as they appear on a small scale. It remains unclear if these changes are in fact induced by the presence of the fog or vice versa, that the fog is due to some ambient mesoscale phenomena. In the third category, the fog appears in association with a frontal passage (before or after) but no change in air mass could be detected in the boundary layer during the fog. As near-surface observations are mostly useless to detect frontal passages, due to the very strong surface control of the Arctic boundary layer, this distinction could only be made using the soundings in combination with the profiling remote sensing instruments (Tjernström, 2005).

The resulting six fog-defining parameters yielding 15 fog periods were ANT $=0.01 \mathrm{~cm}^{-3}$, AMT $=0.02 \mathrm{~g} \mathrm{~m}^{-3}, N 1=5$, $N 2=1, N 3=5$ and $N 4=6$. Obviously, very thin fogs had a maximum effect on the aerosol. The 15 fog periods defined time windows with varying lengths in absolute time. In order to lend some statistical significance to the extracted fog effects on the aerosol the aerosol time series were searched with these 15 time windows for periods that had the same lengths but satisfied the constraint $N_{\mathrm{d}}<$ ANT throughout, that is, were fog free. In 2001, 35 periods fulfilled this criterion of which 14 time windows occurred fog free more than once in the total time series. 


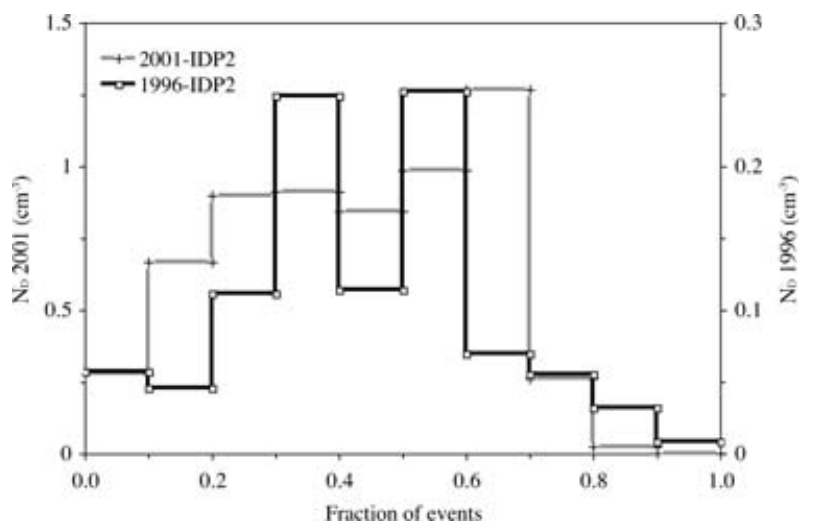

Fig. 6. Median total drop number concentrations $>3 \mu \mathrm{m}$ drop diameter in $\mathrm{cm}^{-3}$ as a function of the fraction of fog event in 1996 and 2001. In 1996 (2001) 13 (11) fog events with travel times Mtr > $24 \mathrm{~h}$ from the ice edge complied with the set fog criteria (cf. text).

Modal aerosol statistics during these 35 fog-free periods were then compared with those of the 15 fog periods.

When applying the 2001 values of the six fog-defining parameters to the 1996 time series no fog period complied because the fogs in 1996 were considerably thinner as compared to 2001. The fixed position of the FSSP in 1996 may also have caused additional losses of larger drops. Thus, the threshold AMT had to be lowered to $0.0006 \mathrm{~g} \mathrm{~m}^{-3}$ in order to yield at least ten fog periods (18 were found). Again, modal aerosol statistics were calculated for corresponding fog-free reference periods, of which 63 were found in 1996.

Figure 6 gives the median total drop concentrations as a function of the fraction of the fog periods in 1996 and 2001. Peak values were almost an order of magnitude smaller in 1996 compared to 2001. They were reached around the middle of the average fog event whereas maximum values of $N_{\mathrm{d}}$ were reached between $60 \%$ and $70 \%$ of the length of the average fog event in 2001.

In Fig. 7 normalized median modal concentrations in the Aitken size range for 1996 and 2001 are compared to the corresponding values during fog-free periods. For both types of time periods, plotting the 25th and 75th percentiles indicates aerosol variability. Without fog-related aerosol processes we would expect a random fluctuation of the ratio $N_{\text {Mod }} / N_{\text {Mod,median }}$ about the medians as indicated by the span between the percentiles during fog-free periods. In both years this span covers a range of $\pm 30 \%$ about the median.

If only scavenging processes were active we would expect a decrease of $N_{\text {Mod }} / N_{\text {Mod, median }}$ below the median during the strongest parts of the fog events. The evolution of Aitken numbers during fog events, however, followed quite a different path. In both years the 75 th percentile reached peak values of about twice the median between $30 \%$ and $50 \%$ of the average fog event, that is, before the maximum in drop number. The fact that four out of five fog criteria being the same in both years yielded strong
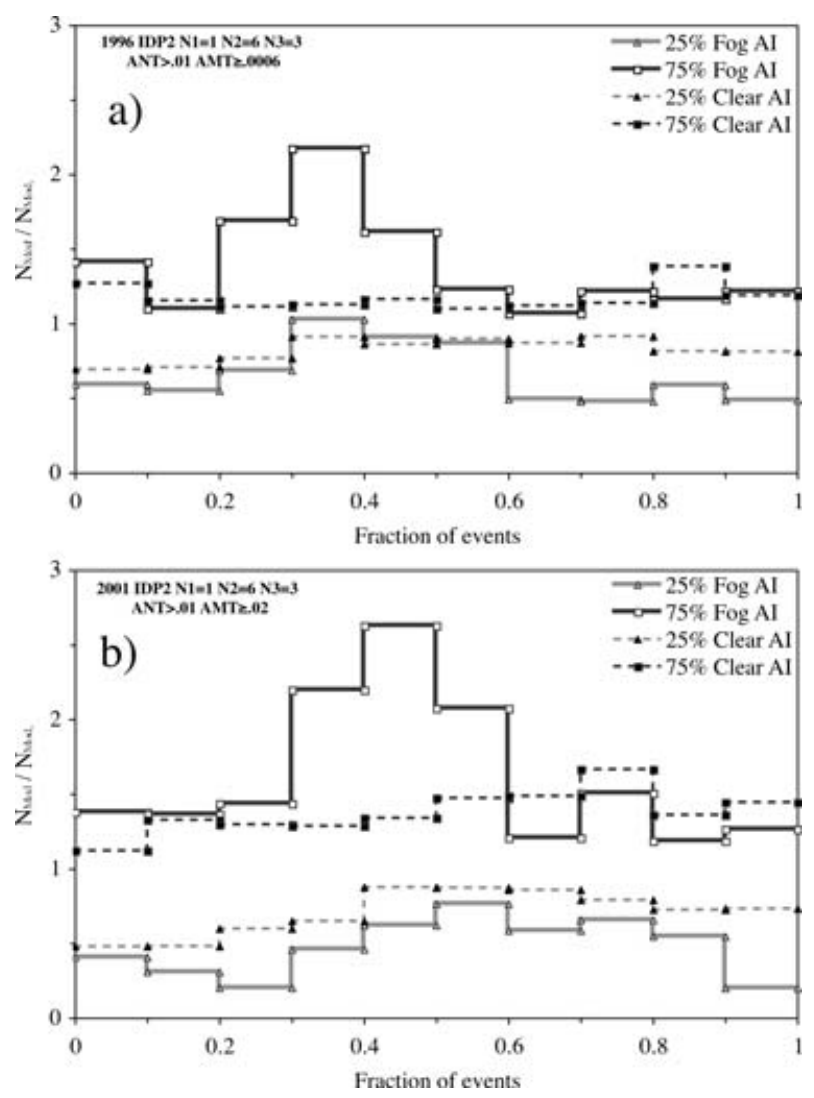

Fig. 7. (a) Normalized median modal concentrations for the Aitken mode (AI) as a function of the fraction of fog events in 1996 satisfying the fog criteria stated in the text and with travel times from the ice edge Mtr $>24 \mathrm{~h}$ and (b) same but for the year 2001. Top thick line stands for the 75th percentile whereas the lower thick line stands for the 25 th percentile. Thin dashed lines give the corresponding statistical parameters for clear periods of the same lengths.

temporal increases in Aitken concentrations during the onset of fogs, which we interpret as strong indications of fog-related aerosol source processes along the lines discussed in Leck and Bigg (1999). One might speculate that the much thinner fogs in 1996 were likely to lead to more evaporation taking place in 1996 than in 2001 when much more dense fogs were present. Leck and Bigg (1999) postulate the production of new particles under conditions of evaporating fogs. One could then expect on the basis of the Leck and Bigg (1999) hypothesis, that there should be larger increases in Aitken particles in the 1996 fog events compared to those in 2001. However, a comparison between the findings of Figs $7 \mathrm{a}$ and $7 \mathrm{~b}$, reveals that there is greater enhancement of normalized median modal Aitken concentrations (compared to fog-free events) in 2001 compared to 1996, opposite to what one might expect on the basis of the evaporating fog particle production mechanism of Leck and Bigg (1999). The present statistical analysis, however, cannot elucidate specific source processes. Moreover, there were significant differences 
in the fog measurement approaches in 1996 and 2001, which may in part be responsible for the different results.

\section{Summary and conclusions}

The present study covers submicrometer aerosol size distribution data taken during three Arctic icebreaker expeditions in the summers of 1991, 1996 and 2001. The main part of the working regions of all three expeditions was the pack-ice-covered high Arctic north of $83^{\circ} \mathrm{N}$ for which no other aerosol data exist. Whereas the 1991 data had been published previously, the 1996 and 2001 data have not been published before. The size distributions of all expeditions were harmonized and compared in log-normally fitted form to the statistics of the marine number size distribution provided by Heintzenberg et al. (2004) yielding rather similar log-normal parameters of the four modes named ultrafine, Aitken, accumulation and large accumulation for fogfree periods north of $74^{\circ} \mathrm{N}$.

The unique working area of the three expeditions allowed systematic studies of aerosol properties as a function of the time the air spend over the pack ice since last contact with the open seas and the marginal ice zone (travel time), which traditionally has been seen as free of particle sources. Statistics of the modal concentrations revealed strong concentration decreases of large accumulation mode particles with increasing length of time spent over the pack ice. No clear trend with travel time was found in the accumulation mode. For Aitken and ultrafine modes strong concentration increases at different travel times far beyond the ice edge were recorded. In 1991, for example, peak ultrafine concentrations were found at travel times beyond $120 \mathrm{~h}$ from the ice edge. The travel-time dependencies of both Aitken and ultrafine modes strongly indicate the occurrence of fine-particle sources. Other studies have indicated that these sources originate in the surface film of the open water between ice floes (Bigg et al. (2004); Leck and Bigg (2005)).

With two approaches evidence of fog-related aerosol source processes as hypothesized by Leck and Bigg (1999) was sought for in the data sets of 1996 and 2001 because they included fog drop size distributions. In the first approach size-dependent frequencies of occurrence of modal concentrations during fogs with different thresholds of drop concentrations were compared to respective data from fog-free periods. With increasing fog intensity modes in interstitial particle number concentrations appeared in particular in the size range around $80 \mathrm{~nm}$ that was nearly mode free in clear air.

In a second, dynamic approach, fog periods were defined objectively with six parameters including thresholds of drop number and LWC, length of fog period and, importantly, the length of fog-free period after fog dissolution. When including 60 fog-free post-fog minutes average Aitken mode concentrations increased strongly above their respective fog-period medians in both years before maximum drop numbers were reached in both years. We interpret the results of both approaches as strong indications of fog-related aerosol source processes as discussed in Leck and Bigg (1999) that need to be elucidated with further data from dedicated fog experiments in future Arctic expeditions in order to understand the life cycle of the aerosol over the high Arctic pack ice area.

\section{Acknowledgments}

We highly appreciate Pasi Aalto's operating the aerosol size distribution and FSSP measurements during the 1996 expedition. Corinne Fischer kindly operated the aerosol size distribution measurements in 2001. D. Theiss of the Leibniz Institute for Tropospheric Research drafted Fig. 1. Jussi Paatero of the Finish Meteorological Institute operated the FSSP in 2001 and kindly processed the data.

\section{References}

Barrie, L., Ahier, B., Bottenheim, J., Niki, H. and Nriagu, J. 1992. Atmospheric methane and sulphur compounds at a remote Central Canadian location. Atmos. Env. 26A, 907-925.

Bigg, E. K., Leck, C. and Tranvik, L. 2004. Particulates of the surface microlayer of open water in the central Arctic Ocean in summer. Mar. Chem. 91, 131-141.

Birmili, W., Stratmann, F. and Wiedensohler, A. 1999. Design of a DMAbased size spectrometer for a large particle size range and stable operation. J. Aerosol. Sci. 30, 549-553.

Clarke, A. D., Varner, J. L., Eisele, F., Mauldin, R. L. and Tanner, D. 1998. Particle production in the remote marine atmosphere: cloud outflow and subsidence during ACE 1. J. Geophys. Res. 103, 16 397-16 409.

Clarke, A. D., Kapustin, V. N., Eisele, F. L., Weber, R. J. and McMurry, P. H. 1999. Particle production near marine clouds: sulfuric acid and predictions from classical binary nucleation. Geophys. Res. Lett. 26, 2425-2428.

Covert, D. S., Wiedensohler, A., Aalto, P., Heintzenberg, J., McMurry, P. H. and co-authors. 1996. Aerosol number size distributions from 3 to $500 \mathrm{~nm}$ diameter in the arctic marine boundary layer during summer and autumn. Tellus 48B, 197-212.

Curry, J. A. 1986. Interactions among turbulence, radiation and microphysics in Arctic stratus clouds. J. Atmos. Sci. 43, 90-106.

Heintzenberg, J. and Larssen, S. 1983. $\mathrm{SO}_{2}$ and $\mathrm{SO}_{4}$ in the Arctic: interpretation of observations at three Norwegian Arctic-subArctic stations. Tellus 35B, 255-265.

Heintzenberg, J. and Leck, C. 1994. Seasonal variation of the atmospheric aerosol near the top of the marine boundary layer over Spitsbergen related to the Arctic sulphur cycle. Tellus 46B, 52-67.

Heintzenberg, J., Wendisch, M., Yuskiewicz, B., Orsini, D., Wiedensohler, A. and co-authors. 1998. Characteristics of haze, mist and fog. Contrib. Atmos. Phys. 71, 21-30.

Heintzenberg, J., Birmili, W., Wiedensohler, A., Nowak, A. and Tuch, T. 2004. Structure, variability and persistence of the submicrometer marine aerosol. Tellus 56B, 357-367.

Huschke, R. E. 1969. Arctic cloud statistics from "air calibrated" surface weather observations. Rand Corporation Memo, RM 6173-PR, 79.

Intrieri, J. M., Shupe, M. D., Uttal, T. and McCarty, B. J. 2002. An annual cycle of Arctic cloud characteristics observed by radar and lidar at SHEBA. J. Geophys. Res. 107, doi 10.1029/2000JC000423. 
Kumai, M. 1973. Arctic fog droplet size distribution and its effect on light attenuation. J. Atmos. Sci. 30, 635-643.

Lannefors, H., Heintzenberg, J. and Hansson, H.-C. 1983. A comprehensive study of physical and chemical parameters of the Arctic summer aerosol; results from the Swedish expedition Ymer-80. Tellus 35B, $40-54$.

Leck, C., Bigg, E. K., Covert, D. S., Heintzenberg, J., Maenhaut, W. and co-authors.. 1996. Overview of the atmospheric research program during the International Arctic Ocean Expedition of 1991 (IAOE-91) and its scientific results. Tellus 48B, 136155.

Leck, C. and Persson, C. 1996a. Seasonal and short-term variability in dimethyl sulfide, sulfur dioxide and biogenic sulfur and sea salt aerosol particles in the arctic marine boundary layer, during summer and autumn. Tellus 48B, 272-299.

Leck, C. and Persson, C. 1996b. The central Arctic Ocean as a source of dimethyl sulfide Seasonal variability in relation to biological activity. Tellus 48B, 156-177.

Leck, C. and Bigg, E. K. 1999. Aerosol production over remote marine areas-a new route. Geophys. Res. Lett. 23, 3577-3581.

Leck, C. and Bigg, E. K. 2005. Biogenic particles in the surface microlayer and overlaying atmosphere in the central Arctic Ocean during summer. Tellus 57B, 205-316.

Leck, C., Nilsson, E. D., Bigg, E. K. and Bäcklin, L. 2001. The atmospheric program on the Arctic Ocean Expedition 1996 (AOE-96): an overview of scientific goals, experimental approach, and instruments. J. Geophys. Res. 106, 32 051-32 067.

Leck, C., Tjernström, M., Matrai, P., Swietlicki, E. and Bigg, K. 2004. Can marine micro-organisms influence melting of the Arctic pack ice? EOS 85, 25-36.

Maenhaut, W., Ducastel, G., Leck, C., Nilsson, E. D. and Heintzenberg, J. 1996. Multielemental composition and sources of the high Arctic atmospheric aerosol during summer and autumn 1991. Tellus 48B, 300-321.

McGrath, R. 1989. Trajectory Models and Their Use in the Irish Meteorological Service. Irish Meteorological Service, Dublin, 112/89.

Nilsson, E. D. 1996. Planetary boundary layer structure and air mass transport during the International Arctic Ocean Expedition 1991. Tellus 48B, 178-196.

Radke, L. F. and Hobbs, P. V. 1991. Humidity and particle fields around some small cumulus clouds. J. Atmos. Sci. 48, 1190-1193.

Stolzenburg, M. R. 1988. An Ultrafine Aerosol Size Distribution Measuring System. PhD Thesis. University of Minnesota, Minneapolis, Minnesota.

Tjernström, M., Leck, C., Persson, P. O. G., Jensen, M. L. and Oncley, S. P. 2004a. The summertime Arctic atmosphere: meteorological Measurements during the Arctic Ocean Experiment 2001. Bull. Amer. Meteor. Soc. 85, 1305-1321.

Tjernström, M., Leck, C., Persson, P. O. G., Jensen, M. L., Oncley, S. P. and co-authors 2004b. Experimental equipment: a Supplement to "The summertime Arctic Atmosphere: meteorological measurements during the Arctic Ocean Experiment 2001". Bull. Am. Meteorol. Soc. 85, doi:10.1175-BAMS-85-9-Tjernstrom.

Tjernström, M. 2005. The summer Arctic boundary layer during the Arctic Ocean Experiment 2001 (AOE-2001). Bound.-Layer Meteor. (in press).

Wiedensohler, A., Covert, D., Swietlicki, E., Aalto, P., Heintzenberg, J. and co-authors.. 1996. Occurrence of an ultrafine particle mode less than $20 \mathrm{~nm}$ in diameter in the marine boundary layer of the Arctic summer and autumn. Tellus 48B, 213-222.

Wiedensohler, A., Hansson, H.-C., Orsini, D., Wendisch, M., Wagner, F. and co-authors. 1997. Night-time formation and occurrence of new particles associated with orographic clouds. Atmos. Env. 31, 25452559 . 